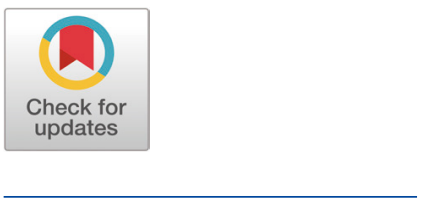

Received: Apr 25, 2020

Revised: May 20, 2020

Accepted: May 26, 2020

*Corresponding author

Fujiang Hou

State Key Laboratory of Grassland

Agro-ecosystems, Key Laboratory

of Grassland Livestock Industry

Innovation, Ministry of Agriculture,

College of Pastoral Agriculture Science

and Technology, Lanzhou University,

Lanzhou 730020, China.

Tel: +86-0931-8913047

E-mail: cyhoufj@|zu.edu.cn

Copyright $(02020$ Korean Society of

Animal Sciences and Technology.

This is an Open Access article

distributed under the terms of the

Creative Commons Attribution

Non-Commercial License (http://

creativecommons.org/licenses/by-

nc/4.0/) which permits unrestricted

non-commercial use, distribution, and

reproduction in any medium, provided

the original work is properly cited.

ORCID

Chuntao Yang

https://orcid.org/0000-0002-4354-2606

Guru Tsedan

https://orcid.org/0000-0001-8624-3799

Yang Liu

https://orcid.org/0000-0001-6098-496X

Fujiang Hou

https://orcid.org/0000-0002-5368-7147

Competing interests

No potential conflict of interest relevant

to this article was reported.

Funding sources

This work was supported by the

Strategic Priority Research Program

of Chinese Academy of Sciences

\section{Shrub coverage alters the rumen bacterial community of yaks (Bos grunniens) grazing in alpine meadows}

\author{
Chuntao Yang ${ }^{1}$, Guru Tsedan², Yang Liu ${ }^{1}$ and Fujiang $\mathrm{Hou}^{1 *}$
}

${ }^{1}$ State Key Laboratory of Grassland Agro-ecosystems, Key Laboratory of Grassland Livestock Industry
Innovation, Ministry of Agriculture, College of Pastoral Agriculture Science and Technology, Lanzhou
University, Lanzhou 730020, China
${ }^{2}$ Animal Husbandry Science and Technology Demonstration Park of Maqu County, Gannan 743000, China

Abstract

Proliferation of shrubs at the expense of native forage in pastures has been associated with large changes in dry-matter intake and dietary components for grazing ruminants. These changes can also affect the animals' physiology and metabolism. However, little information is available concerning the effect of pastoral-shrub grazing on the rumen bacterial community. To explore rumen bacteria composition in grazing yaks and the response of rumen bacteria to increasing shrub coverage in alpine meadows, 48 yak steers were randomly assigned to four pastures with shrub coverage of $0 \%, 5.4 \%, 11.3 \%$, and $20.1 \%$ (referred as control, low, middle, and high, respectively), and ruminal fluid was collected from four yaks from each pasture group after 85 days. Rumen fermentation products were measured and microbiota composition determined using lon $\mathrm{S} 5^{\mathrm{TM}} \mathrm{XL}$ sequencing of the $16 \mathrm{~S}$ rRNA gene. Principal coordinates analysis (PCoA) and similarity analysis indicated that the degree of shrub coverage correlated with altered rumen bacterial composition of yaks grazing in alpine shrub meadows. At the phyla level, the relative abundance of Firmicutes in rumen increased with increasing shrub coverage, whereas the proportions of Bacteroidetes, Cyanobacteria and Verrucomicrobia decreased. Yaks grazing in the high shrub-coverage pasture had decreased species of the genus Prevotellaceae UCG-001, Lachnospiraceae XPB1014 group, Lachnospiraceae AC2044 group, Lachnospiraceae FCS020 group and Fretibacterium, but increased species of Christensenellaceae R-7 group, Ruminococcaceae NK4A214 group, Ruminococcus 1, Ruminococcaceae UCG-002, Ruminococcaceae UCG-005 and Lachnospiraceae UCG-008. These variations can enhance the animals' utilization efficiencies of cellulose and hemicellulose from native forage. Meanwhile, yaks grazed in the high shrub-coverage pasture had increased concentrations of ammonia nitrogen $\left(\mathrm{NH}_{3}-\mathrm{N}\right)$ and branched-chain volatile fatty acids (isobutyrate and isovalerate) in rumen compared with yaks grazing in the pasture without shrubs. These results indicate that yaks grazing in a high shrub-coverage pasture may have improved dietary energy utilization and enhanced resistance to cold stress during the winter. Our findings provide evidence for the influence of shrub coverage on the rumen bacterial community of yaks grazing in alpine meadows as well as insights into the sustainable production of grazing yaks on lands with increasing shrub coverage on the Qinghai-Tibet Plateau. Keywords: Alpine shrub meadow, Bacterial community, Qinghai-Tibet Plateau, Shrub, Yak 
(XDA2010010203), the National Natural Science Foundation of China (31172249), and the Program for Changjiang Scholars and Innovative Research Team in University (IRT17R50)

\section{Acknowledgements}

Not applicable.

Availability of data and material Upon reasonable request, the datasets of this study can be available from the corresponding author.

Authors' contributions

Conceptualization: Hou F.

Data curation: Yang C, Hou F.

Formal analysis: Yang $\mathrm{C}$.

Methodology: Yang C, Hou F.

Software: Yang $\mathrm{C}$.

Validation: Hou F.

Investigation: Yang C, Tsedan G, Liu Y.

Writing - original draft: Yang $C$.

Writing - review \& editing: Hou F.

Ethics approval and consent to participate All procedures strictly followed the rules and regulations of the Experimental Field Management protocols of the Lanzhou University and were approved by the Animal Ethics Committee of the Lanzhou University.

\section{INTRODUCTION}

Rumen is a complex microbial ecosystem, and rumen microorganisms play important roles in the fermentation of plant proteins and polysaccharides [1,2]. Bacteria account for more than $95 \%$ of the total number of rumen microorganisms, and their metabolic byproducts— such as volatile fatty acids (VFA), amino acids and microbial proteins-have a significant effect on animal health and growth [3-5]. Although different rumen bacterial populations have distinct metabolisms, changes in the host animal diet or grazing regime can have a major influence on rumen microbial makeup $[2,6]$. Meanwhile, the diet can directly affect the ruminant's growth, immune-system function, and competition between commensal bacteria and opportunistic pathogens [7-9], all of which contribute to the challenge of understanding the rumen microbial ecosystem.

Grasslands are a major vegetation-soil type, covering 20\% of the total land surface on Earth, and contribute substantially to global livestock production [10]. However, a striking change in the types of vegetation on grasslands has occurred worldwide in recent decades as a result of proliferation of trees or shrubs at the expense of native forage. This change has occurred in North and South America [11,12], Africa [13], Australia [14], and Eurasia [15]. An increase in shrub coverage in pastures has often been associated with large changes in dry-matter intake and dietary components for grazing ruminants $[12,16,17]$. Additionally, pastoral shrubs may contain plant secondary metabolites, such as condensed tannins $[18,19]$, which can negatively affect both physiology and metabolism. Consequently, such changes may influence the composition of the rumen bacterial community and hence rumen fermentation. Zhou et al. [20] showed that adding tannic acid into beef cattle diet increased the relative abundance of Tenericutes and the proportions of Succiniclasticum and Saccbarofermentans in rumen. Meanwhile, it has been reported that a group of bacteria present in the rumen possesses tannin degrading ability, such as Streptococcus gallolyticus [21,22], Selenomonas ruminantium [23] and Clostridium [24].

The Qinghai-Tibetan Plateau (QTP) is the largest grassland ecosystem in Eurasia and is openly grazed by more than 13.3 million domestic yaks (Bos grunniens) [10,25]. Unfortunately, between 1990 and 2009, at least 39\% of QTP meadows were encroached by shrubs [15], and the annual encroachment rate $(2.1 \%)$ is very high when compared with other areas $(0.1 \%-2.3 \%$ per year) of broad-scale shrub expansion [11,26]. We found that although the grazing behavior and serum biochemical parameters of yaks were not influenced by the degree of shrub coverage in the pastures, the body condition and body weight gain of yaks declined with increasing shrub coverage of pasture on the QTP (Yang et al., unpublished data). These observations suggest that the extent of shrub coverage in pastures may affect both rumen bacterial community structure and fermentation. Previous studies have investigated the effect of shrubs as dietary supplements on feedstuff degradation, gas production, and rumen fermentation both in vitro [27-30] and in vivo [19,31,32]. For example, Salem et al. [28] and Pal et al. [29] reported that supplement leaves containing high content of tannin with the ruminants would decrease ammonia nitrogen $\left[\mathrm{NH}_{3}-\mathrm{N}\right]$ and total VFA concentrations, whereas, Kholif et al. [31] and Bhatta et al. [33] suggested that ruminants fed high crude protein (CP) content shrub leaves with low tannin content enhanced the total VFA and $\mathrm{NH}_{3}-\mathrm{N}$ concentrations in the rumen. However, little information is available concerning the effect of pastoral-shrub grazing on rumen bacterial community and the correlations between rumen fermentation and bacterial communities for grazing ruminants. Furthermore, extrapolation of in vitro measurements to in vivo conditions in ruminants would be complex and likely inaccurate [34,35]. Therefore, we hypothesized that the rumen microbiota would differ in yaks grazing in pastures containing different levels of shrub coverage and that variations in the microbiota could produce different microbial fermentation metabolites (e.g., $\mathrm{NH}_{3}-\mathrm{N}, \mathrm{VFA}$ ) that contribute to body condition and growth 
performance. The objective of the present study was to compare the rumen bacterial composition between yaks grazing in alpine shrub meadows having different amounts of shrub coverage using $16 \mathrm{~S}$ rRNA sequencing and to assess the correlations between the rumen bacterial communities and fermentation products.

\section{MATERIALS AND METHODS}

All procedures strictly followed the rules and regulations of the Experimental Field Management protocols (file No: 2010-1 and 2010-2) of the Lanzhou University and were approved by the Animal Ethics Committee of the Lanzhou University.

\section{Study site}

The study was carried out at the Maqu Grassland Agriculture Trial Station of Lanzhou University, Maqu County, Gansu Province, China ( $33^{\circ} 06^{\prime}$ to $34^{\circ} 33^{\prime} \mathrm{N}, 100^{\circ} 46^{\prime}$ to $102^{\circ} 29^{\prime}$ E; elevation 3,500 m), located in the northeast QTP. The mean annual temperature during the experimental period was $3.5^{\circ} \mathrm{C}$ and total rainfall was $603 \mathrm{~mm}$. The native vegetation is typical of alpine meadows. The primary foliage is perennial herbaceous plants, including Kobresia spp. (e.g., K. graminifolia, K. capillifolia, $K$. humilis, and K. tibetica), Elymus sp. (i.e., E. nutans), Potentilla L. sp. (i.e., P. anserina), Stipa spp. (e.g., S. aliena), Festuca spp. (e.g., F. ovina), and the shrub Potentilla fruticosa L. (Rosaceae) (P. fruticose). The proportions of herbage biomass were $42 \%$ Kobresia spp., $19 \%$ E. nutans, $6 \%$ S. aliena, $11 \%$ F. ovina, and 5\% P. anserine, as reported by Yang et al. [25]. Leaves of P. fruticosa contained $48.7 \pm 9.2 \%$ (mean \pm standard deviation $[\mathrm{SD}]$ ) dry matter, and (dry-matter basis) $11.0 \pm 2.7 \% \mathrm{CP}, 65.5 \pm 1.5 \%$ neutral detergent fiber, $31.7 \pm 1.8 \%$ acid detergent fiber, $18.3 \pm 0.2 \mathrm{MJ} / \mathrm{kg}$ gross energy, $3.1 \pm 0.9 \%$ ether extract, and $4.3 \pm 0.2 \%$ condensed tannins.

\section{Experimental design and animals}

The study was conducted from July 1 to September 30, 2017. Four types of grasslands were included based on the extent of their shrub cover. The mean shrub cover values for the four regions were characterized by visual examination by three independent observers as $0,5.4 \%, 11.3 \%$, and $20.1 \%$ and were referred to as Control, Low, Middle, and High, respectively. Each treatment area (10 ha) was divided into three blocks as rotationally grazed pastures.

Forty-eight yak steers were used for the study: body weight $=114.6 \pm 4.1 \mathrm{~kg}($ mean $\pm \mathrm{SD})$, average age $=2$ years. They were divided into four groups according to body weight and age (12 animals/treatment). Before starting the experiment, all steers were dewormed and introduced into their experimental environment for 7 days. They were grazed (grazing rate of $3.6 \mathrm{yaks} / \mathrm{ha}$ ) as individual treatment groups (12 yaks/group) on their designed blocks from 08:00 to 17:30 $\mathrm{h}$ and housed in shelters overnight. The yaks were rotationally grazed among three blocks within each area for 1 week for each block. Native forage was sampled every 2 weeks during the 85-day experimental period; the chemical composition of the forage is shown in Table 1. All yaks had free access to fresh water and a mineral-lick block (Cangzhou Leysin Biotechnology) during the experimental period.

\section{Rumen sample collection and measurements}

Four yaks of similar average body weight in each treatment group were selected for collection of ruminal content (liquid and particulate forage material), which was sampled in the morning before grazing at the end of the experiment. Samples (approximately $100 \mathrm{~mL}$ ) were collected using an oral stomach tube as described by Shen et al. [36]. The device was thoroughly cleaned between sample collections using fresh water, and the first 50-mL of the sample from each yak was always discarded 
Table 1. Effects of shrub coverage on chemical composition (DM basis unless otherwise stated, \%) of forage in alpine meadows

\begin{tabular}{|c|c|c|c|c|c|c|c|c|}
\hline \multirow{2}{*}{ Item } & \multicolumn{4}{|c|}{ Shrub coverage } & \multirow{2}{*}{ SEM } & \multicolumn{3}{|c|}{$p$-value } \\
\hline & Control & Low & Middle & High & & Treatment & Linear & Quadratic \\
\hline DM (\% as fresh) & 39.15 & 40.99 & 39.60 & 40.20 & 1.082 & 0.843 & 0.841 & 0.612 \\
\hline $\mathrm{CP}$ & 10.31 & 10.46 & 9.01 & 9.33 & 0.461 & 0.636 & 0.306 & 0.956 \\
\hline Gross energy (MJ/kg DM) & 17.16 & 17.19 & 17.39 & 16.73 & 0.143 & 0.378 & 0.582 & 0.218 \\
\hline Organic matter & 92.95 & 92.90 & 93.58 & 93.50 & 1.395 & 0.650 & 0.270 & 0.937 \\
\hline NDF & 63.14 & 63.30 & 63.66 & 62.32 & 1.563 & 0.822 & 0.646 & 0.470 \\
\hline ADF & 62.52 & 61.77 & 62.22 & 60.00 & 1.019 & 0.462 & 0.449 & 0.480 \\
\hline WSC & 13.22 & 13.01 & 13.45 & 12.88 & 0.331 & 0.450 & 0.681 & 0.327 \\
\hline Ether extract & 3.23 & 3.34 & 3.07 & 3.10 & 0.077 & 0.589 & 0.342 & 0.759 \\
\hline
\end{tabular}

SEM, standard error of the mean; DM, dry matter; CP, crude protein; NDF, neutral detergent fiber; ADF, acid detergent fiber; WSC, water soluble carbohydrate.

to ensure it was not contaminated from previous animals and his own saliva, as described by Zhang et al. [4]. The rumen samples were divided into two subsamples. One of the subsamples (20 mL) was immediately frozen in liquid nitrogen and stored at $-80^{\circ} \mathrm{C}$ for later DNA extraction. Another approximately $80-\mathrm{mL}$ sample was immediately subjected to $\mathrm{pH}$ measurement with a portable $\mathrm{pH}$ meter (Model 206-pH2, Testo, Germany) and then strained through four layers of sterile gauze. The filtrate was collected and stored at $-20^{\circ} \mathrm{C}$ for later measurement of total VFA and $\mathrm{NH}_{3}-\mathrm{N}$. For analysis of VFA concentrations, the filtrate was thawed and centrifuged at 1,000×g for $15 \mathrm{~min}$ and then analyzed using gas chromatography (chromatograph SP-3420A, Beifenrili Analyzer Associates, Beijing, China) as described by Yang et al. [37]. Ruminal $\mathrm{NH}_{3}-\mathrm{N}$ concentration was determined by colorimetry (spectrophotometer U-2900, Hitachi, Tokyo, Japan) as described by Hristov et al. [38].

\section{DNA extraction}

Frozen rumen samples were thawed at room temperature and homogenized before DNA extraction using TN150 buffer (10 mM Tris- $\mathrm{HCl} \mathrm{pH} \mathrm{8.0,150} \mathrm{mM} \mathrm{NaCl)} \mathrm{with} \mathrm{a} \mathrm{bead-beating} \mathrm{step,}$ as described by $\mathrm{Li}$ et al. [39]. Briefly, each rumen sample (containing rumen liquid and particulate forage material) was transferred to a $15-\mathrm{mL}$ tube containing $4.5 \mathrm{~mL}$ TN150 buffer, vortexed for 30 $\mathrm{s}$, and centrifuged at $200 \times \mathrm{g}$ for $5 \mathrm{~min}$ at $4^{\circ} \mathrm{C}$. The supernatant was then transferred to a $2-\mathrm{mL} \mathrm{mi-}$ crocentrifuge tube containing zirconium beads $(0.3 \mathrm{~g}, 0.1 \mathrm{~mm}$ diameter) followed by centrifugation and oscillation. The amount and quality of DNA was assessed by agarose gel (1\%) electrophoresis and measuring the 260:280 nm absorbance ratio with an ND-1000 spectrophotometer (NanoDrop Technologies, Wilmington, DE, USA).

\section{Sequencing, sequence processing and analysis}

The V3-V4 region of the bacterial 16S rRNA gene was amplified using the universal primer set 338F (5'-ACTCCTRCGGGAGGCAGCAG-3') and 806R (5'-GGACTACCVGGGTATCTAAT-3') [40]. Barcodes of an eight-base sequence unique to each sample were added to each primer for sample identification. PCR was performed in triplicate as follows: an initial denaturing step of $95^{\circ} \mathrm{C}$ for $3 \mathrm{~min}$, followed by 30 cycles at $95^{\circ} \mathrm{C}$ for $30 \mathrm{~s}, 55^{\circ} \mathrm{C}$ for $30 \mathrm{~s}$, and $72^{\circ} \mathrm{C}$ for 40 s, with final extension at $72{ }^{\circ} \mathrm{C}$ for $10 \mathrm{~min}$. Amplicons were extracted from $2 \%$ agarose gels and purified using an GeneJET ${ }^{\mathrm{TM}}$ Gel Extraction kit (Thermo Scientific, Schwerte, Germany). Sequencing libraries were generated using the Ion Plus Fragment Library kit 48 rxns (Thermo Scientific, Schwerte, Germany). Library quality was assessed with a Qubit@ 2.0 Fluorometer (Thermo Scientific), and the library was sequenced with an Ion $\mathrm{S}^{\mathrm{TM}} \mathrm{XL}$ platform. The resultant 400-bp/600- 
bp single-end reads were assigned to samples based on their unique barcode and truncated by cutting off the barcode and primer sequence. Quality filtering of the raw reads was performed with the CUTADAPT (version 1.9.1) quality-control process [41]. Chimera sequences were identified and removed using the UCHIME algorithm [42]. Sequences with $\geq 97 \%$ similarity were clustered as the same operational taxonomic units (OTUs) using UPARSE (version 7.0) [43]. Taxonomy was aligned by RDP classifier (version 2.2) and compared with the SILVA (SSU123) 16S rRNA Database [44]. Community alpha diversity was measured with the normalized OTUs (copy number-based) using the observed species, Good's coverage, Chao1, the abundance-based coverage estimator, and Shannon and Simpson indices by QIIME (version 1.7.0). The PCoA with weighted and unweighted UniFrac distance matrices and the analysis of similarity in QIIME were used to estimate differences in bacterial communities between samples. Raw sequence data are available in NCBI Sequence Read Archive under BioProject ID PRJNA622912.

\section{Statistical analysis}

The Shapiro-Wilk test was used to assess the normality of data before comparing mean values. Data of Simpson index were sine-transformed to achieve normality. The chemical composition of forage, rumen $\mathrm{pH}$ and fermentation parameters, bacterial relative abundance, and alpha diversity indices were analyzed using one-way analysis of variance with SAS (version 9.2, SAS Institute, Cary, NC, USA). Differences between mean values were considered significant when $p<0.05$.

Pearson correlation coefficients between bacterial communities and rumen fermentation parameters were calculated using the PROC CORR procedure of SAS 9.2 with a heatmap format as described by Pan et al. [45]. Briefly, only those bacterial taxa with an abundance $>0.1 \%$ of the total community in at least one ruminal sample were used in the analysis. The abundances of bacterial communities at the genus level and ruminal parameters were considered to be correlated with each other for correlation coefficient values $(|\mathrm{r}|) \geq 0.55$ and $p<0.05[46]$.

\section{RESULTS}

\section{Rumen fermentation parameters}

There was no significant difference in rumen $\mathrm{pH}$, total VFA, proportions of acetate, propionate and butyrate, and ratio of acetate:propionate among the four groups of yaks $(p>0.05$; Table 2$)$.

Table 2. Effects of shrub coverage on rumen $\mathrm{pH}$ and fermentation parameters of yaks grazed on an alpine meadow

\begin{tabular}{|c|c|c|c|c|c|c|c|c|}
\hline \multirow{2}{*}{ Item } & \multicolumn{4}{|c|}{ Shrub coverage } & \multirow{2}{*}{ SEM } & \multicolumn{3}{|c|}{$p$-value } \\
\hline & Control & Low & Middle & High & & Treatment & Linear & Quadratic \\
\hline Rumen pH & 5.65 & 5.75 & 5.27 & 5.82 & 0.128 & 0.886 & 0.990 & 0.403 \\
\hline $\mathrm{NH}_{3}-\mathrm{N}(\mathrm{mg} / 100 \mathrm{~mL})$ & $4.48^{\mathrm{b}}$ & $4.69^{b}$ & $9.36^{a}$ & $9.48^{a}$ & 0.802 & 0.008 & 0.004 & 0.970 \\
\hline Total VFA (mmol/mL) & 95.7 & 84.6 & 130.5 & 116.4 & 9.74 & 0.356 & 0.247 & 0.938 \\
\hline Acetate (\%) & 72.8 & 74.1 & 70.1 & 70.6 & 0.89 & 0.483 & 0.219 & 0.840 \\
\hline Propionate (\%) & 16.4 & 15.4 & 16.5 & 15.7 & 0.38 & 0.845 & 0.811 & 0.911 \\
\hline Butyrate (\%) & 7.53 & 7.07 & 9.08 & 8.54 & 0.403 & 0.067 & 0.188 & 0.959 \\
\hline Isobutyrate (\%) & $1.11^{\mathrm{b}}$ & $1.13^{b}$ & $1.36^{\mathrm{ab}}$ & $1.68^{\mathrm{a}}$ & 0.096 & 0.042 & 0.038 & 0.404 \\
\hline Isovalerate (\%) & $1.58^{\mathrm{b}}$ & $1.67^{b}$ & $2.12^{\mathrm{ab}}$ & $2.58^{\mathrm{a}}$ & 0.156 & 0.041 & 0.018 & 0.716 \\
\hline Valerate (\%) & $0.59^{\mathrm{b}}$ & $0.64^{\mathrm{ab}}$ & $0.87^{\mathrm{a}}$ & $0.86^{a}$ & 0.048 & 0.028 & 0.017 & 0.513 \\
\hline Acetate:propionate & 4.52 & 4.83 & 4.39 & 4.52 & 0.169 & 0.808 & 0.791 & 0.810 \\
\hline
\end{tabular}

a,b Values within a row with different superscripts differ significantly at $p<0.05$.

SEM, standard error of the mean; $\mathrm{NH}_{3}-\mathrm{N}$, ammonia nitrogen; VFA, volatile fatty acids. 
However, rumen $\mathrm{NH}_{3}-\mathrm{N}$ concentration in the Middle and High groups was higher than in the Control and Low groups $(p=0.008)$. Proportions of isobutyrate, isovalerate and valerate in rumen significantly increased with increasing shrub coverage, with differences observed between High and Control or Low group for isobutyrate $(p=0.042)$ and isovalerate $(p=0.041)$, and between Control and Middle or High group for valerate $(p=0.028)$.

\section{Composition of bacterial communities in rumen fluid}

A total of 1,293,181 raw reads was obtained from 16 samples. Quality filtering at 97\% similarity resulted in 1,225,593 high-quality sequences that clustered in 2,043 OTUs after normalization, with an average of $1,845 \pm 134$ OTUs per sample. Taxonomic analysis of the reads revealed 18 bacterial phyla, with Firmicutes and Bacteroidetes being the predominant phyla, accounting for $46.14 \%$ and 43.95\%, respectively, of the total sequences (Fig. 1). Spirochaetes, Cyanobacteria, Proteobacteria, Fibrobacteres, and SR1 were present at 1.92\%, 1.39\%, 1.25\%, 1.13\%, and 1.10\%, respectively, of the total sequences. The proportions of some phyla, e.g., Tenericutes, Verrucomicrobia, Synergistetes, Elusimicrobia, was less than $1 \%$ of the total microbial community.

In terms of alpha diversity (Fig. 2), although no difference was observed across the four experimental groups for the observed species, Good's coverage, Chao1, the abundance-based coverage estimator, and Simpson and Shannon indexes $(p>0.05)$, the Good's coverage for all samples exceeded $98 \%$, indicating that the sequencing depth was comparable and accurate across the four groups.

The PCoA plots based on weighted and unweighted UniFrac distance metrics were constructed to compare differences among the groups (Fig. 3). The PCoA result showed that the data for yaks of the High group differed significantly from the data for yaks in the Control and Low groups. Further analysis of similarity (Table 3 ) revealed a significant difference in bacterial community structure between the Control $(R=0.615, p=0.027)$ or Low $(R=0.635, p=0.041)$ group and the High group, indicating that the degree of shrub coverage in the pasture influences the composition of the bacterial community in the rumen.

The effects of pasture shrub coverage on the prevalence of certain bacterial phyla (top 10) in yak rumen are presented in Table 4. The relative abundance of Firmicutes significantly increased with increasing shrub coverage $(p=0.001)$, whereas the proportions of Bacteroidetes, Cyanobacteria and Verrucomicrobia decreased $(p \leq 0.046)$. Yaks in the Low group had higher relative abundances of

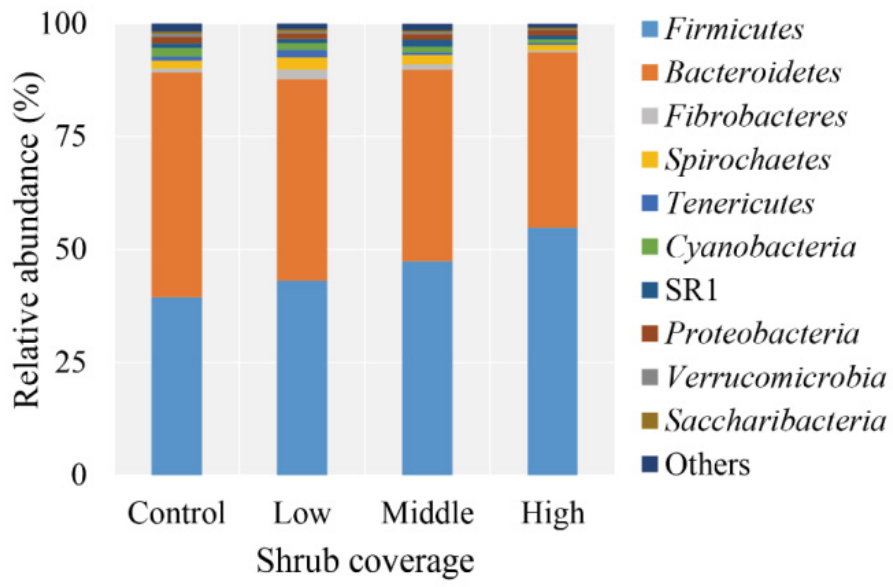

Fig. 1. Percent relative abundance of the top 10 predominant bacterial phyla in ruminal samples of yaks grazing in alpine meadows. 

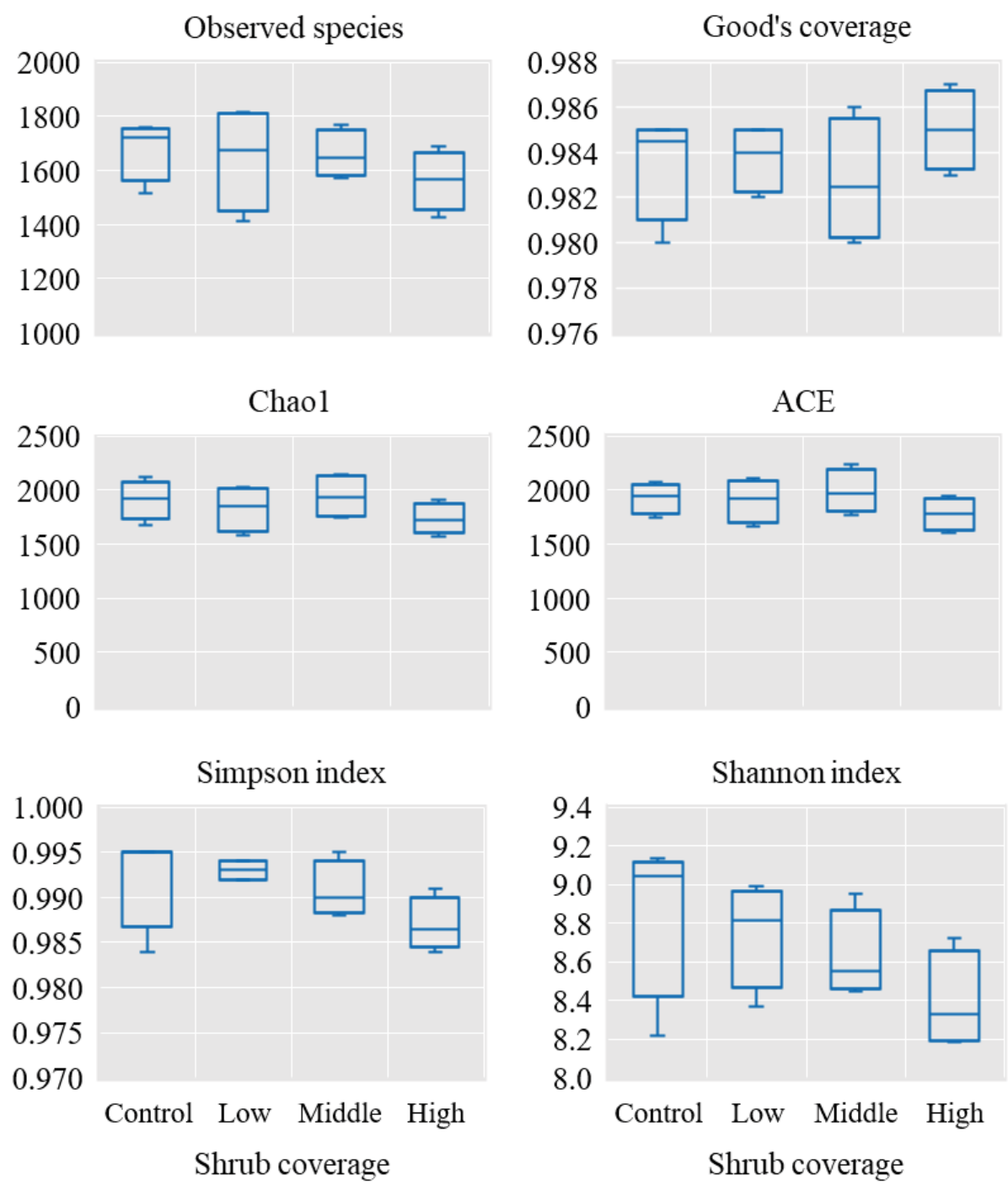

Fig. 2. Effects of shrub coverage on the alpha diversity index for bacteria in ruminal samples of yaks grazing in alpine meadows. Data of Simpson index were sine-transformed to achieve normality.

Fibrobacteres $(p=0.024)$ and Tenericutes $(p=0.042)$ compared with animals in the other groups. At the genus level, 181 taxa were identified, and the proportions of 15 genera (with relative abundance of $\geq 0.1 \%$ in at least one sample) differed among the four experimental groups (Table 5). Animals in the High group had significantly higher relative abundances of Christensenellaceae R-7 group, $R u$ minococcaceae NK4A214 group, Ruminococcus 1, Ruminococcaceae UCG-002, Ruminococcaceae UCG005, and Lachnospiraceae UCG-008 ( $p$ < 0.047) but lesser proportions of Prevotellaceae UCG-001, Lachnospiraceae XPB1014 group, Lachnospiraceae AC2044 group, Lachnospiraceae FCS020 group, and Fretibacterium $(p \leq 0.048)$. The relative abundance of genus Erysipelotrichaceae UCG-004 in the Low group was higher than that in the Middle and High groups $(p=0.015)$. The proportions of Pseudobutyrivibrio $(p=0.019)$ and Oribacterium $(p=0.013)$ in the Middle group were higher than those in the Control and Low groups, whereas the relative abundance of Lachnospiraceae NK4A136 group was higher than that in the Control and High groups $(p=0.011)$. 

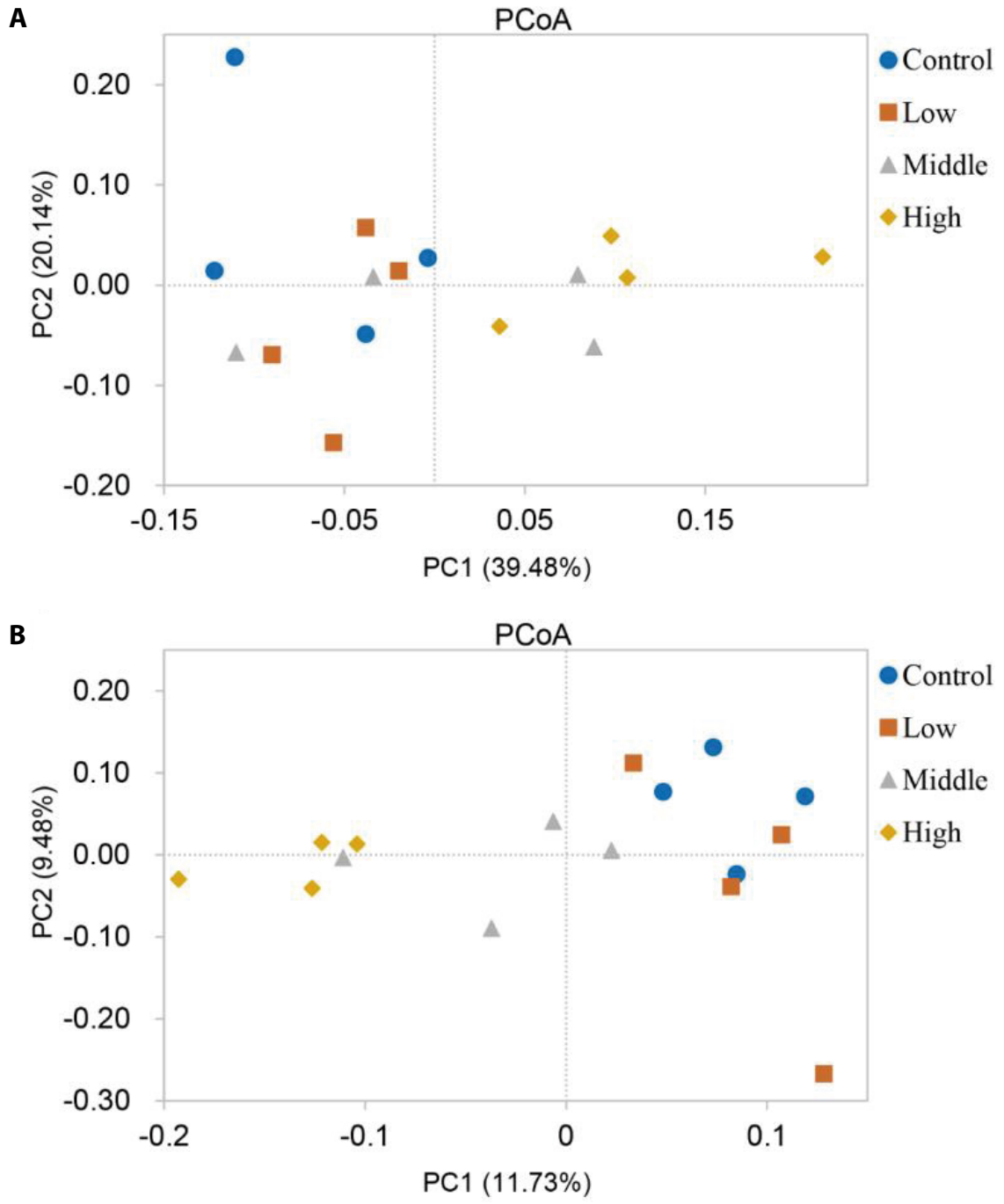

Fig. 3. Principal coordinates analysis ( $P C \circ A)$ of bacterial community structures in ruminal samples of yaks grazing in alpine meadows. PCoA plots were constructed based on weighted $(A)$ and unweighted (B) UniFrac distance metrics. Control, group grazed in meadows lacking shrubs; Low, low shrub-coverage group; Middle, middle shrub-coverage group; High, high shrub-coverage group.

Table 3. Analysis of similarity (ANOSIM) for bacterial community structures in ruminal samples of yaks grazed in alpine meadows

\begin{tabular}{|c|c|c|c|c|c|c|}
\hline \multirow{2}{*}{ Item } & \multicolumn{2}{|c|}{ Control } & \multicolumn{2}{|c|}{ Low } & \multicolumn{2}{|c|}{ Middle } \\
\hline & $R$-value & $p$-value & $R$-value & $p$-value & $R$-value & $p$-value \\
\hline Low & -0.250 & 0.934 & - & - & - & - \\
\hline Middle & 0.073 & 0.330 & -0.042 & 0.733 & - & - \\
\hline High & 0.615 & 0.027 & 0.635 & 0.041 & 0.333 & 0.064 \\
\hline
\end{tabular}

Control, group grazed in meadows lacking shrubs; Low, low shrub-coverage group; Middle, middle shrub-coverage group; High, high shrub-coverage group.

Correlations between bacterial communities and rumen fermentation parameters Rumen $\mathrm{NH}_{3}-\mathrm{N}$ concentration correlated positively with the relative abundance of the genus Oribacterium ( $r=0.608, p=0.013$; Fig. 4) but negatively with Erysipelotrichaceae UCG-004, Prevotellaceae UCG-001, and Anaeroplasma ( $r<-0.55, p<0.05$ ). The genus Erysipelotrichaceae UCG-004 and probable genus 10 correlated positively with acetate concentration $(r>0.55, p<0.05)$, whereas 
Table 4. Effect of shrub coverage on relative abundances (\%) of the top 10 predominant bacterial phyla in ruminal samples of yaks grazing in alpine meadows

\begin{tabular}{|c|c|c|c|c|c|c|}
\hline \multirow{2}{*}{ Item } & \multicolumn{4}{|c|}{ Shrub coverage } & \multirow{2}{*}{ SEM } & \multirow{2}{*}{$p$-value } \\
\hline & Control & Low & Middle & High & & \\
\hline Firmicutes & $39.40^{\mathrm{b}}$ & $43.05^{b}$ & $47.35^{\mathrm{ab}}$ & $54.78^{a}$ & 4.989 & 0.001 \\
\hline Bacteroidetes & $49.77^{\mathrm{a}}$ & $44.69^{\mathrm{ab}}$ & $42.48^{\mathrm{ab}}$ & $38.87^{b}$ & 3.673 & 0.046 \\
\hline Spirochaetes & 1.73 & 2.65 & 2.06 & 1.26 & 0.192 & 0.282 \\
\hline Cyanobacteria & $1.94^{\mathrm{a}}$ & $1.48^{\mathrm{ab}}$ & $1.27^{\mathrm{ab}}$ & $0.87^{\mathrm{b}}$ & 0.138 & 0.043 \\
\hline Proteobacteria & 1.42 & 1.18 & 1.22 & 1.18 & 0.117 & 0.126 \\
\hline Fibrobacteres & $0.86^{\mathrm{b}}$ & $2.11^{\mathrm{a}}$ & $1.17^{\mathrm{b}}$ & $0.38^{b}$ & 0.043 & 0.024 \\
\hline SR1 & 0.99 & 0.96 & 1.54 & 0.90 & 0.109 & 0.126 \\
\hline Tenericutes & $0.91^{b}$ & $1.68^{\mathrm{a}}$ & $0.56^{\mathrm{b}}$ & $0.36^{b}$ & 0.051 & 0.042 \\
\hline Verrucomicrobia & $0.73^{\mathrm{a}}$ & $0.39^{b}$ & $0.42^{b}$ & $0.22^{b}$ & 0.043 & 0.033 \\
\hline Saccharibacteria & 0.45 & 0.51 & 0.31 & 0.28 & 0.032 & 0.212 \\
\hline Firmicutes:Bacteroidetes & $0.81^{\mathrm{b}}$ & $0.96^{b}$ & $1.14^{\mathrm{ab}}$ & $1.44^{\mathrm{a}}$ & 0.083 & 0.028 \\
\hline
\end{tabular}

a,b Values within a row with different superscripts differ significantly at $p<0.05$.

SEM, standard error of the mean.

Table 5. Effect of shrub coverage on relative abundances (\%) of bacterial genera in ruminal samples of yaks grazing in alpine meadows ${ }^{1)}$

\begin{tabular}{|c|c|c|c|c|c|c|c|c|}
\hline \multirow{2}{*}{ Phylum } & \multirow{2}{*}{ Family } & \multirow{2}{*}{ Genus } & \multicolumn{4}{|c|}{ Shrub coverage } & \multirow{2}{*}{ SEM } & \multirow{2}{*}{$p$-value } \\
\hline & & & Control & Low & Middle & High & & \\
\hline Bacteroidetes & Prevotellaceae & Prevotellaceae UCG-001 & $2.09^{\mathrm{a}}$ & $1.99^{\mathrm{a}}$ & $1.54^{\mathrm{ab}}$ & $1.07^{b}$ & 0.142 & 0.020 \\
\hline \multirow[t]{13}{*}{ Firmicutes } & Christensenellaceae & Christensenellaceae R-7 group & $6.08^{b}$ & $7.09^{\mathrm{b}}$ & $6.87^{b}$ & $10.59^{\mathrm{a}}$ & 0.638 & 0.037 \\
\hline & Ruminococcaceae & Ruminococcaceae NK4A214 group & $5.14^{b}$ & $6.24^{b}$ & $7.00^{\mathrm{b}}$ & $12.65^{\mathrm{a}}$ & 0.990 & 0.014 \\
\hline & & Ruminococcus 1 & $0.64^{b}$ & $0.63^{b}$ & $1.07^{\mathrm{a}}$ & $1.18^{\mathrm{a}}$ & 0.087 & 0.021 \\
\hline & & Ruminococcaceae UCG-002 & $0.35^{\mathrm{b}}$ & $0.24^{\mathrm{b}}$ & $0.39^{b}$ & $0.75^{\mathrm{a}}$ & 0.073 & 0.043 \\
\hline & & Ruminococcaceae UCG-005 & $0.80^{\mathrm{b}}$ & $0.84^{\mathrm{b}}$ & $1.74^{\mathrm{b}}$ & $4.12^{\mathrm{a}}$ & 0.439 & 0.006 \\
\hline & Erysipelotrichaceae & Erysipelotrichaceae UCG-004 & $1.09^{\mathrm{ab}}$ & $1.76^{\mathrm{a}}$ & $0.50^{\mathrm{b}}$ & $0.24^{b}$ & 0.200 & 0.015 \\
\hline & Lachnospiraceae & Pseudobutyrivibrio & $0.72^{b}$ & $0.66^{\mathrm{b}}$ & $1.53^{\mathrm{a}}$ & $1.11^{\mathrm{ab}}$ & 0.121 & 0.019 \\
\hline & & Lachnospiraceae XPB1014 group & $0.67^{\mathrm{ab}}$ & $1.24^{\mathrm{a}}$ & $1.08^{\mathrm{a}}$ & $0.43^{b}$ & 0.124 & 0.048 \\
\hline & & Lachnospiraceae AC2044 group & $0.50^{\mathrm{ab}}$ & $0.71^{\mathrm{a}}$ & $0.49^{\mathrm{ab}}$ & $0.25^{b}$ & 0.061 & 0.041 \\
\hline & & Lachnospiraceae NK4A136 group & $0.24^{b}$ & $0.26^{\mathrm{ab}}$ & $0.36^{a}$ & $0.16^{b}$ & 0.025 & 0.011 \\
\hline & & Oribacterium & $0.21^{b}$ & $0.31^{\mathrm{b}}$ & $0.54^{\mathrm{a}}$ & $0.40^{\mathrm{ab}}$ & 0.041 & 0.013 \\
\hline & & Lachnospiraceae UCG-008 & $0.09^{b}$ & $0.07^{\mathrm{b}}$ & $0.12^{b}$ & $0.26^{\mathrm{a}}$ & 0.027 & 0.047 \\
\hline & & Lachnospiraceae FCS020 group & $0.07^{\mathrm{bc}}$ & $0.14^{\mathrm{a}}$ & $0.12^{\mathrm{ab}}$ & $0.05^{c}$ & 0.012 & 0.012 \\
\hline Synergistetes & Synergistaceae & Fretibacterium & $0.49^{\mathrm{a}}$ & $0.22^{\mathrm{bc}}$ & $0.44^{\mathrm{ab}}$ & $0.10^{c}$ & 0.057 & 0.020 \\
\hline
\end{tabular}

${ }^{1)}$ Only bacterial genera (accounting for $\geq 0.1 \%$ in at least one of the samples) that were affected by shrub coverage are listed.

${ }^{a-q}$ Values within a row with different superscripts differ significantly at $p<0.05$.

SEM, standard error of the mean.

Erysipelotrichaceae UCG-004 correlated negatively with valerate concentration $(r=-0.556, p=$ 0.025). The concentrations of isobutyrate and isovalerate correlated negatively with Erysipelotrichaceae UCG-004, Prevotellaceae UCG-003, Prevotellaceae UCG-001, Anaeroplasma, Lachnospiraceae AC2044 group and probable genus $10(r<-0.55, p<0.05)$, but isobutyrate concentration correlated positively with Ruminococcaceae UCG-005 ( $r=0.559, p=0.024)$ and Oribacterium $(r=0.578, p=$ 0.019). There was no significant correlation between the relative abundance of genera and $\mathrm{pH}$, total VFA, or concentration of propionate or butyrate $(|r|<0.55, p>0.05)$. 


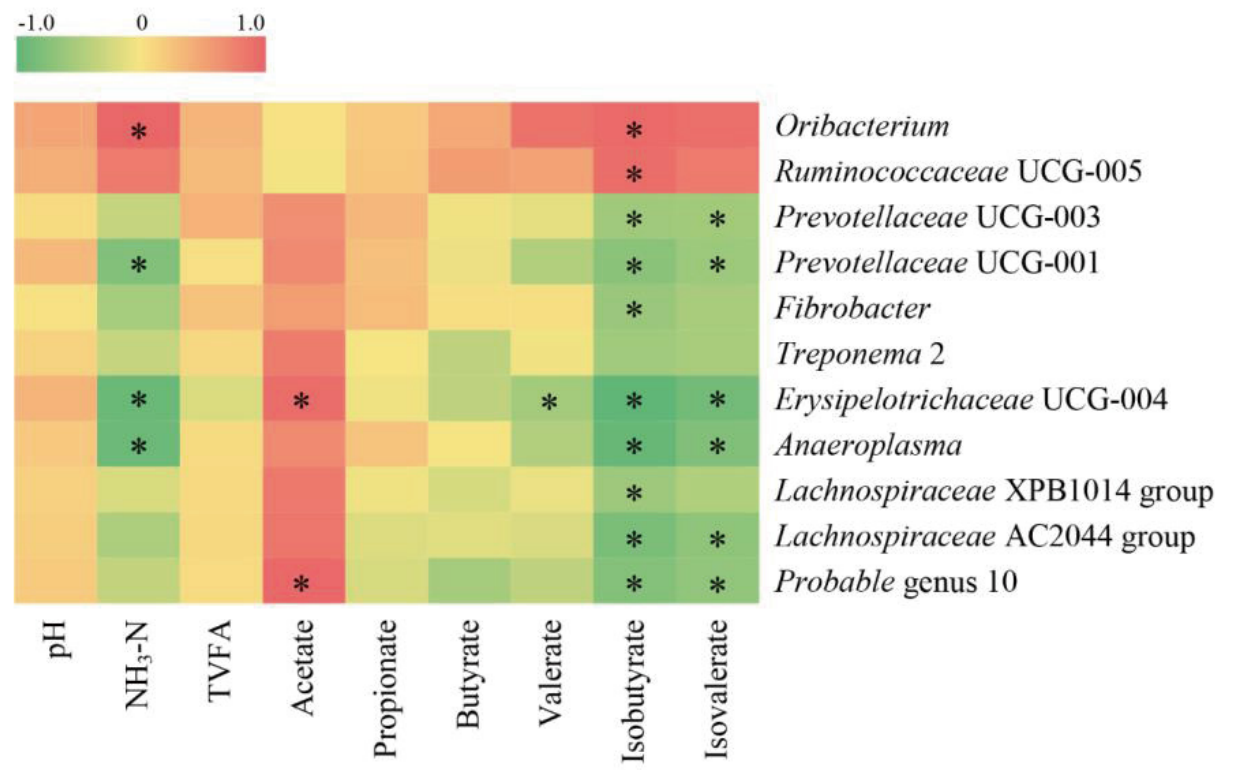

Fig. 4. Correlation analyses between relative abundances of bacterial genera (present at $\geq 0.1 \%$ in at least one sample) and fermentation parameters of yaks grazing in alpine meadows. $\mathrm{NH}_{3}-\mathrm{N}$, ammonia nitrogen; TVFA, total volatile fatty acids. " $p<0.05$.

\section{DISCUSSION}

\section{Effects of pasture shrub coverage on rumen fermentation}

Physiology and metabolism (e.g., altered microbial activity, reduced digestion, compromised acid/ base balance, toxicity) of animals were affected by consuming shrubs because of the existence of condensed tannins in leaves $[18,19]$. Negative effects to the animals range from harmless to lethal depending on factors such as dose, animal species, level of nutrition and physiological state $[19,47,48]$. Tannin content in the rumen liquid and subsequent detrimental effects on blood biochemistry have not been observed for yaks grazing in pastures with various levels of shrub coverage (Yang et al., unpublished data), indicating that either the amount of plant secondary metabolites ingested by the yaks was negligible, or that the ability of organisms to detoxify secondary metabolites has a vital role in the homeostasis of their body systems [49].

In the present study, although the chemical compositions of forage were not affected by the shrub coverage of the pasture (Table 1), rumen from yaks grazing in high shrub-coverage pastures had increased $\mathrm{NH}_{3}-\mathrm{N}$ concentrations and higher proportions of isobutyrate, isovalerate and valerate compared with yaks grazing in pastures without shrubs. Branched-chain VFA (e.g., isobutyrate, isovalerate) are normally formed from degradation of branched-chain amino acids [50], and increasing amounts of branched-chain VFA in rumen indicate increased fermentation of protein [27]. It has been reported that shrub leaves generally contain abundant nutrients (e.g., $\mathrm{CP}$, minerals, vitamins) and biologically active compounds (e.g., polysaccharides), which increase the amount of fermentable substrate available to the ruminal microflora [51,52]. Hence, we speculated that a higher quantity of fresh shrub leaves containing high $\mathrm{CP}$ content might be consumed by the yaks grazing in the high shrub-coverage pasture. Kholif et al. [31] and Bhatta et al. [33] reported that ruminants fed high CP-content leaves with low or no tannin content had higher concentrations of VFA and $\mathrm{NH}_{3}-\mathrm{N}$ in rumen. In addition, Bohnert et al. [53] used an in vitro fermentation method to verify that low-quality (high fiber content and low $\mathrm{CP}$ content) forage diet with protein supplementation 
significantly increased the rumen $\mathrm{NH}_{3}-\mathrm{N}$ and VFA concentrations compared with non-supplementation. These results were supported by in vivo data for yaks [54,55]. Although shrub intake was not measured in the present study, the observed higher rumen $\mathrm{NH}_{3}-\mathrm{N}$ concentration with increasing shrub coverage in the pasture might support this concept. Indeed, the major shrub species $(P$. fruticosa) found in the present study has a higher CP content (11.0\%) compared with native forage (9.7\%). Additionally, the changes of $\mathrm{NH}_{3}-\mathrm{N}$ concentration in rumen among the groups could be attributable to variation of rumen microorganism of yaks grazing in pastures with different levels of shrub coverage.

\section{Characterization of rumen bacteria in yaks grazing in shrub pastures}

To understand the relationship between the consumption of pastoral shrubs and rumen fermentation, we used high-throughput sequencing to investigate the response of the bacterial community in yak rumen to increased shrub coverage in the alpine meadows where these animals graze. In the present study, Firmicutes and Bacteroidetes were the most predominant bacteria phyla in the rumen of these yaks, as reported previously [2,5,56,57]. At the genus level, Prevotella 1, Rikenellaceae RC9 gut group, Ruminococcaceae (NK4A214 group, UCG-010, UCG-005 and UCG-014), Christensenellaceae R-7 group, Prevotellaceae (UCG-003 and UCG-001), Fibrobacter, Saccharofermentans, Treponema 2, Selenomonas 1, Succiniclasticum and Butyrivibrio 2 constituted both the core bacterial community and main bacteria in the rumen, which mirror previous results $[2,57,58]$. The higher proportion of these genera enable their members to occupy various ecological niches and make full use of nutrients within the rumen [40,59]. Among them, the family Ruminococcaceae and the genera Fibrobacter, Treponema 2 and Butyrivibrio 2 are known to be cellulolytic bacteria [4,57,60], whereas Prevotellaceae is known for the utilization of starch and protein [61]. Rikenellaceae RC9 gut group as a main genus of Rikenellaceae plays a role in the fermentation of carbohydrates and protein [62]. Chen et al. [63] reported that Saccharofermentans can utilize glucose as a substrate for fermentation to produce acetate. Selenomonas 1 and Succiniclasticum are the main participants in the fermentation of succinate to form propionate, which is the most important precursor of glucose in ruminants $[3,64]$. Similar to previous reports, however, little is known regarding the function of the genus Christensenellaceae R-7 group [45,65].

\section{Effects of pasture shrub coverage on rumen bacterial composition}

Although the alpha diversity metrics of rumen bacterial community were not influenced by the degree of shrub coverage in pastures, a significant difference of bacterial community structure in yak rumen was found in the present study between animals grazing in pastures with high shrub coverage and those with low or no shrub coverage. PCoA and analysis of similarity indicated that high shrub-coverage pasture could alter the yak rumen bacterial community composition.

Bacteroidetes are responsible for proteolysis, carbohydrate degradation and fermentation of amino acids into acetate [66,67]. Turnbaugh et al. [68] and Chen et al. [69] reported that Firmicutes perform essential functions in energy conversion and harvesting. In the present study, the relative abundance of Firmicutes significantly increased in the rumen of yaks grazing in pastures with higher levels of shrub coverage, whereas the proportions of Bacteroidetes, Cyanobacteria, Verrucomicrobia decreased. The increasing Firmicutes members and ratio of Firmicutes to Bacteroidetes in rumen indicated that yaks grazing in high shrub-coverage pastures may improve dietary energy utilization and have increased resistance to cold stress during the winter [70]. Studies have verified that there is a strong relationship between the ratio of Firmicutes to Bacteroidetes and body fat storage in humans and mice [71-73]. Also, obesity in animals is thought to be related to an increase in the ratio of Firmicutes to Bacteroidetes [56,74]. The lower abundances of Bacteroidetes, Cyanobacteria and 
Verrucomicrobia in rumen from yaks grazing in high shrub-coverage pastures could be the result of competitive inhibition of substrate (e.g., nitrogen or carbon sources) with an increasing abundance of Firmicutes [75], thus limiting proliferation of these lower-abundance species. Additionally, we speculated that the changes in abundance of Cyanobacteria, Fibrobacteres, Tenericutes and Verrucomicrobia in the rumen among the groups could be attributable to variation in diet and geographical environment of yaks grazing in pastures with different shrub coverage or the interaction of both.

At the genus level, Christensenellaceae R-7 group, Ruminococcaceae NK4A214 group, Ruminococcus 1, Ruminococcaceae UCG-002, Ruminococcaceae UCG-005, Lachnospiraceae UCG-008 were detected in higher abundance in the high shrub-coverage group compared to that in other groups. Among them, Ruminococcaceae are an important group of bacteria inhabiting the rumen and is able to degrade plant cell wall polysaccharides into metabolizable energy [76]. Meanwhile, a meta-analysis revealed that Ruminococcaceae and Lachnospiraceae are the predominant ruminal bacteria in ruminants fed forage diet and might have important roles in ruminal fiber digestion [65,77]. The results indicated that yaks grazing in the alpine shrub meadows with increasing shrub coverage might have enhanced abilities to utilize cellulose and hemicellulose from native forage. Additionally, we observed that Ruminococcaceae UCG-005 and Oribacterium correlated positively with isobutyrate concentration in yak rumen. Bainbridge et al. [6] reported that bacteria in rumen could synthesize branched-chain fatty acids de novo through the elongation of propionate and valerate or the alteration of $\alpha$-keto acids. Shrub leaves containing abundant nutrients and biologically active compounds can potentially enhance fiber degradation through the action of Ruminococcaceae UCG005 and Oribacterium [2,51,52]. Therefore, the higher abundances of Ruminococcaceae and Oribacterium might have caused an enhanced concentration of isovalerate in rumen of yaks with increasing shrub coverage in the pastures. Meanwhile, a higher $\mathrm{CP}$ content in shrub leaves could provide an additional source of nitrogen as a fermentation substrate for these bacteria, thus resulting in increased $\mathrm{NH}_{3}-\mathrm{N}$ levels in rumen. Additionally, Russell and Jeraci [78] and Russell and Martin [79] reported that $\mathrm{NH}_{3}-\mathrm{N}$ production was enhanced in rumen, primarily as a consequence of increased branched-chain amino acid fermentation. Conversely, the proportions of Lachnospiraceae XPB 1014 group, Lachnospiraceae AC2044 group and Lachnospiraceae FCS020 group were lower in rumen of yak grazing in high shrub-coverage pastures than in other treatment pastures, indicating that genera within the family Lachnospiraceae have different shrub sensitivities. Branched-chain VFA, such as isobutyrate and isovalerate, are normally derived from the fermentation of branched-chain amino acids and may be an obligate nutritional requirement for some rumen bacteria [80,81]. Nolan [82] suggested that most species of rumen bacteria could obtain carbon skeletons from branched-chain VFA and use $\mathrm{NH}_{3}-\mathrm{N}$ as a sole source of nitrogen for growth. In the present study, we observed lower concentrations of isobutyrate and isovalerate in the control and low shrub-coverage groups, and negative correlations between Prevotellaceae UCG-003, Prevotellaceae UCG-001, Erysipelotrichaceae UCG-004, Anaeroplasma, Prevotellaceae AC2044 group or probable genus 10 and isobutyrate, isovalerate or $\mathrm{NH}_{3}-\mathrm{N}$ concentrations. These observations may have been the result of the utilization of branched-chain VFA by these bacteria. In addition, the abundance of genus Christensenellaceae R-7 group was increased in the rumen of yaks grazing in high shrub-coverage pastures, but the reasons for the altered status of this genera in yaks grazing in pastures with different amounts of shrub coverage are unclear because little is known regarding the functions of Christensenellaceae R-7 group $[45,65]$. However, we speculated that the higher relative abundances of these bacteria in rumen of yaks grazing on high shrub coverage might be related to the ability to degrade or tolerate tannins. Similarly, a number of studies have indicated that ruminal bacteria belonging to Streptococcus, Leuconostoc, Lactobacillus, Megasphaera, Prevotella, Selenomonas, Butyrovibrio, Clostridium and Enterobacter sp. were capable of degrading tannin in vitro or in vivo [21-24]. 


\section{CONCLUSION}

In this study, shrub coverage in grazing pastures correlated with changes in the rumen bacterial community structure of yaks grazing in alpine shrub meadows as evidenced by changes in the abundances of phyla Firmicutes, Bacteroidetes, Cyanobacteria and Verrucomicrobia in the rumen. Compared with control and low shrub-coverage pastures, yaks grazing in high shrub-coverage pasture had enhanced utilization efficiencies for structural carbohydrates from native forage as a result of increased abundances of genus Christensenellaceae R-7 group, Ruminococcaceae NK4A214 group, Ruminococcus 1, Ruminococcaceae UCG-002, Ruminococcaceae UCG-005 and Lachnospiraceae UCG-008. These results suggest that yaks grazing in high shrub-coverage pastures may have improved dietary energy utilization and increased resistance to cold stress during the winter. Additionally, yaks grazed in high shrub-coverage pastures had elevated concentrations of $\mathrm{NH}_{3}-\mathrm{N}$ and branched-chain VFAs (isobutyrate and isovalerate) in rumen compared with yaks grazed in pastures without shrubs. The results from the present study may improve our understanding of the influence of pasture shrub coverage on the rumen bacterial community of yaks grazing in alpine meadows and build upon our knowledge relevant to the sustainable production of grazing yaks on the QTP.

\section{REFERENCES}

1. Seshadri R, Leahy SC, Attwood GT, Teh KH, Lambie SC, Cookson AL, et al. Cultivation and sequencing of rumen microbiome members from the Hungate1000 collection. Nat Biotechnol. 2018;36:359-67.

2. Liu C, Wu H, Liu S, Chai S, Meng Q, Zhou Z. Dynamic alterations in yak rumen bacteria community and metabolome characteristics in response to feed type. Front Microbiol. 2019;10:1116.

3. Shabat SKB, Sasson G, Doron-Faigenboim A, Durman T, Yaacoby S, Berg Miller ME, et al. Specific microbiome-dependent mechanisms underlie the energy harvest efficiency of ruminants. ISME J. 2016;10:2958-72.

4. Zhang J, Shi H, Wang Y, Li S, Cao Z, Ji S, et al. Effect of dietary forage to concentrate ratios on dynamic profile changes and interactions of ruminal microbiota and metabolites in Holstein heifers. Front Microbiol. 2017;8:2206.

5. Ren Q, Si H, Yan X, Liu C, Ding L, Long R, et al. Bacterial communities in the solid, liquid, dorsal, and ventral epithelium fractions of yak (Bos grunniens) rumen. Microbiologyopen. 2020;9:e963.

6. Bainbridge ML, Saldinger LK, Barlow JW, Alvez JP, Roman J, Kraft J. Alteration of rumen bacteria and protozoa through grazing regime as a tool to enhance the bioactive fatty acid content of bovine milk. Front Microbiol. 2018;9:904.

7. Sandri M, Manfrin C, Pallavicini A, Stefanon B. Microbial biodiversity of the liquid fraction of rumen content from lactating cows. Animal. 2014;8:572-9.

8. Li F, Wang Z, Dong C, Li F, Wang W, Yuan Z, et al. Rumen bacteria communities and performances of fattening lambs with a lower or greater subacute ruminal acidosis risk. Front Microbiol. 2017;8:2506.

9. Patra AK, Park T, Braun HS, Geiger S, Pieper R, Yu Z, et al. Dietary bioactive lipid compounds rich in menthol alter interactions among members of ruminal microbiota in sheep. Front Microbiol. 2019;10:2038.

10. Yang C, Gao P, Hou F, Yan T, Chang S, Chen X, et al. Relationship between chemical composition of native forage and nutrient digestibility by Tibetan sheep on the Qinghai-Tibetan 
Plateau. J Anim Sci. 2018;96:1140-9.

11. Briggs JM, Knapp AK, Blair JM, Heisler JL, Hoch GA, Lett MS, et al. An ecosystem in transition: causes and consequences of the conversion of mesic grassland to shrubland. BioScience. 2005;55:243-54.

12. Anadón JD, Sala OE, Turner BL, Bennett EM. Effect of woody-plant encroachment on livestock production in North and South America. Proc Natl Acad Sci USA. 2014;111:12948-53.

13. Thomas AD, Elliott DR, Dougill AJ, Stringer LC, Hoon SR, Sen R. The influence of trees, shrubs, and grasses on microclimate, soil carbon, nitrogen, and CO2 efflux: potential implications of shrub encroachment for Kalahari rangelands. Land Degrad Dev. 2018;29:1306-16.

14. Fensham RJ, Fairfax RJ, Archer SR. Rainfall, land use and woody vegetation cover change in semi-arid Australian savanna.J Ecol. 2005;93:596-606.

15. Brandt JS, Haynes MA, Kuemmerle T, Waller DM, Radeloff VC. Regime shift on the roof of the world: alpine meadows converting to shrublands in the southern Himalayas. Biol Conserv. 2013;158:116-27.

16. Browning DM, Archer SR. Protection from livestock fails to deter shrub proliferation in a desert landscape with a history of heavy grazing. Ecol Appl. 2011;21:1629-42.

17. Cipriotti PA, Aguiar MR. Direct and indirect effects of grazing constrain shrub encroachment in semi-arid Patagonian steppes. Appl Veg Sci. 2012;15:35-47.

18. Estell RE. Coping with shrub secondary metabolites by ruminants. Small Rumin Res. 2010;94:1-9.

19. García EM, Cherry N, Lambert BD, Muir JP, Nazareno MA, Arroquy JI. Exploring the biological activity of condensed tannins and nutritional value of tree and shrub leaves from native species of the Argentinean dry chaco.J Sci Food Agric. 2017;97:5021-7.

20. Zhou K, Bao Y, Zhao G. Effects of dietary crude protein and tannic acid on rumen fermentation, rumen microbiota and nutrient digestion in beef cattle. Arch Anim Nutr. 2019;73:30-43.

21. Singh B, Chaudhary LC, Agarwal N, Kamra DN. Phenotypic and phylogentic characterisation of tannin degrading/tolerating bacterial isolates from the rumen of goats fed on pakar (Ficus infectoria) leaves.J Appl Anim Res. 2011;39:120-4.

22. Chaudhary LC, Agarwal N, Verma V, Rikhari K, Kamra DN. Effect of feeding tannin degrading bacteria (Isolate-6) on rumen fermentation, nutrient utilization and growth performance of goats fed on Ficus infectoria leaves. Small Rumin Res. 2011;99:143-7.

23. Skene IK, Brooker JD. Characterization for tannin acylhydrolase activity in the ruminal bacterium Selenomonas ruminantium. Anaerobe. 1995;1:321-7.

24. McSweeney CS, Palmer B, Bunch R, Krause DO. Isolation and characterization of proteolytic ruminal bacteria from sheep and goats fed the tannin-containing shrub legume Calliandra calothyrsus. Appl Environ Microbiol. 1999;65:3075-83.

25. Yang C, Zhang Y, Hou F, Millner JP, Wang Z, Chang S. Grazing activity increases decomposition of yak dung and litter in an alpine meadow on the Qinghai-Tibet Plateau. Plant Soil. 2019;444:239-50.

26. Sankey TT, Germino M. Assessment of juniper encroachment with the use of satellite imagery and geospatial data. Rangel Ecol Manag. 2008;61:412-8.

27. McSweeney CS, Palmer B, Bunch R, Krause DO. In vitro quality assessment of tannin-containing tropical shrub legumes: protein and fibre digestion. Anim Feed Sci Technol. 1999;82:227-41.

28. Salem AZM, Robinson PH, El-Adawy MM, Hassan AA. In vitro fermentation and microbial protein synthesis of some browse tree leaves with or without addition of polyethylene glycol. Anim Feed Sci Technol. 2007;138:318-30. 
29. Pal K, Patra AK, Sahoo A, Kumawat PK. Evaluation of several tropical tree leaves for methane production potential, degradability and rumen fermentation in vitro. Livest Sci. 2015;180:98105.

30. Atalay AI, Ozkan CO, Kaya E, Kurt O, Kamalak A. Effect of maturity on chemical composition and nutritive value of leaves of Arbutus andrachne shrub and rumen in vitro methane production. Livest Res Rural Dev. 2017;29:138.

31. Kholif AE, Gouda GA, Morsy TA, Salem AZM, Lopez S, Kholif AM. Moringa oleifera leaf meal as a protein source in lactating goat's diets: feed intake, digestibility, ruminal fermentation, milk yield and composition, and its fatty acids profile. Small Rumin Res. 2015;129:129-37.

32. Vandermeulen S, Ramírez-Restrepo CA, Beckers Y, Claessens H, Bindelle J. Agroforestry for ruminants: a review of trees and shrubs as fodder in silvopastoral temperate and tropical production systems. Anim Prod Sci. 2018;58:767-77.

33. Bhatta R, Vaithiyanathan S, Singh NP, Shinde AK, Verma DL. Effect of feeding tree leaves as supplements on the nutrient digestion and rumen fermentation pattern in sheep grazing on semi-arid range of India-I. Small Rumin Res. 2005;60:273-80.

34. Kronberg SL, Scholljegerdes EJ, Barceló-Coblijn G, Murphy EJ. Flaxseed treatments to reduce biohydrogenation of $\alpha$-linolenic acid by rumen microbes in cattle. Lipids. 2007;42:1105-11.

35. Flachowsky G, Lebzien P. Comments on in vitro studies with methane inhibitors. Anim Feed Sci Technol. 2009;151:337-9.

36. Shen JS, Chai Z, Song LJ, Liu JX, Wu YM. Insertion depth of oral stomach tubes may affect the fermentation parameters of ruminal fluid collected in dairy cows. J Dairy Sci. 2012;95:5978-84.

37. Yang C, Si B, Diao Q, Jin H, Zeng S, Tu Y. Rumen fermentation and bacterial communities in weaned Chahaer lambs on diets with different protein levels.J Integr Agric. 2016;15:1564-74.

38. Hristov AN, Ivan M, Rode LM, McAllister TA. Fermentation characteristics and ruminal ciliate protozoal population in cattle fed medium- or high-concentrate barley-based diets. J Anim Sci. 2001;79:515-24.

39. Li M, Penner GB, Hernandez-Sanabria E, Oba M, Guan LL. Effects of sampling location and time, and host animal on assessment of bacterial diversity and fermentation parameters in the bovine rumen.J Appl Microbiol. 2009;107:1924-34.

40. Mao S, Zhang M, Liu J, Zhu W. Characterising the bacterial microbiota across the gastrointestinal tracts of dairy cattle: membership and potential function. Sci Rep. 2015;5:16116.

41. Martin M. Cutadapt removes adapter sequences from high-throughput sequencing reads. EMBnet J. 2011;17:10-2.

42. Edgar RC, Haas BJ, Clemente JC, Quince C, Knight R. UCHIME improves sensitivity and speed of chimera detection. Bioinformatics. 2011;27:2194-200.

43. Edgar RC. UPARSE: highly accurate OTU sequences from microbial amplicon reads. Nat Methods. 2013;10:996-8.

44. Quast C, Pruesse E, Yilmaz P, Gerken J, Schweer T, Yarza P, et al. The SILVA ribosomal RNA gene database project: improved data processing and web-based tools. Nucleic Acids Res. 2013;41:D590-6.

45. Pan X, Xue F, Nan X, Tang Z, Wang K, Beckers Y, et al. Illumina sequencing approach to characterize thiamine metabolism related bacteria and the impacts of thiamine supplementation on ruminal microbiota in dairy cows fed high-grain diets. Front Microbiol. 2017;8:1818.

46. Wang W, Li C, Li F, Wang X, Zhang X, Liu T, et al. Effects of early feeding on the host rumen transcriptome and bacterial diversity in lambs. Sci Rep. 2016;6:32479.

47. Mezzomo R, Paulino PVR, Barbosa MM, da Silva-Martins T, Paulino MF, Alves KS, et al. 
Performance and carcass characteristics of young cattle fed with soybean meal treated with tannins. Anim Sci J. 2016;87:775-82.

48. Navon S, Kigel J, Dudai N, Knaanie A, Glasser TA, Shachter A, et al. Volatiles and tannins in Pistacia lentiscus and their role in browsing behavior of goats (Capra hircus). J Chem Ecol. 2020;46:99-113.

49. Surai PF. Polyphenol compounds in the chicken/animal diet: from the past to the future. J Anim Physiol Anim Nutr. 2014;98:19-31.

50. Wolin MJ, Miller TL, Stewart CS. Microbe-microbe interactions. In: Hobson PN, Stewart CS, editors. The rumen microbial ecosystem. London: Blackie Academic and Professional Press; 1997.p. 467-91.

51. Dong S, Long R, Pu X, Hu Z. Availability and utilisation of shrubs as protein sources for yak grazing on alpine meadow on the Qinghai-Tibetan Plateau, PR China. In: Proceedings of the 3rd International Congress on Yak; 2000; Lhasa, China.

52. Patra AK. Effects of supplementing low-quality roughages with tree foliages on digestibility, nitrogen utilization and rumen characteristics in sheep: a meta-analysis. J Anim Physiol Anim Nutr. 2010;94:338-53.

53. Bohnert DW, DelCurto T, Clark AA, Merrill ML, Falck SJ, Harmon DL. Protein supplementation of ruminants consuming low-quality cool-or warm-season forage: differences in intake and digestibility.J Anim Sci. 2011;89:3707-17.

54. Zhang Y, Zhou JW, Guo XS, Cui GX, Ding LM, Wang HC, et al. Influences of dietary nitrogen and non-fiber carbohydrate levels on apparent digestibility, rumen fermentation and nitrogen utilization in growing yaks fed low quality forage based-diet. Livest Sci. 2012;147:139-47.

55. Zhou JW, Liu H, Zhong CL, Degen AA, Yang G, Zhang Y, et al. Apparent digestibility, rumen fermentation, digestive enzymes and urinary purine derivatives in yaks and Qaidam cattle offered forage-concentrate diets differing in nitrogen concentration. Livest Sci. 2018;208:1421.

56. Xue D, Chen H, Chen F, He Y, Zhao C, Zhu D, et al. Analysis of the rumen bacteria and methanogenic archaea of yak (Bos grunniens) steers grazing on the Qinghai-Tibetan Plateau. Livest Sci. 2016;188:61-71.

57. Zhou Z, Fang L, Meng Q Li S, Chai S, Liu S, et al. Assessment of ruminal bacterial and archaeal community structure in yak (Bos grunniens). Front Microbiol. 2017;8:179.

58. Han Z, Li K, Shahzad M, Zhang H, Luo H, Qiu G, et al. Analysis of the intestinal microbial community in healthy and diarrheal perinatal yaks by high-throughput sequencing. Microb Pathog. 2017;111:60-70.

59. Jami E, Mizrahi I. Composition and similarity of bovine rumen microbiota across individual animals. PLOS ONE. 2012;7:e33306.

60. Leng J, Xie L, Zhu R, Yang S, Gou X, Li S, et al. Dominant bacterial communities in the rumen of Gayals (Bos frontalis), Yaks (Bos grunniens) and Yunnan Yellow Cattle (Bos taurs) revealed by denaturing gradient gel electrophoresis. Mol Biol Rep. 2011;38:4863-72.

61. Jami E, Israel A, Kotser A, Mizrahi I. Exploring the bovine rumen bacterial community from birth to adulthood. ISME J. 2013;7:1069-79.

62. Su XL, Tian Q, Zhang J, Yuan XZ, Shi XS, Guo RB, et al. Acetobacteroides hydrogenigenes gen. nov., sp. nov., an anaerobic hydrogen-producing bacterium in the family Rikenellaceae isolated from a reed swamp. Int J Syst Evol Microbiol. 2014;64:2986-91.

63. Chen S, Niu L, Zhang Y. Saccharofermentans acetigenes gen. nov., sp. nov., an anaerobic bacterium isolated from sludge treating brewery wastewater. Int J Syst Evol Microbiol. 2010;60:2735-8. 
64. Fernando SC, Purvis HT, Najar FZ, Sukharnikov LO, Krehbiel CR, Nagaraja TG, et al. Rumen microbial population dynamics during adaptation to a high-grain diet. Appl Environ Microbiol. 2010;76:7482-90.

65. Liu J, Zhang M, Xue C, Zhu W, Mao S. Characterization and comparison of the temporal dynamics of ruminal bacterial microbiota colonizing rice straw and alfalfa hay within ruminants. J Dairy Sci. 2016;99:9668-81.

66. Kong Y, Teather R, Forster R. Composition, spatial distribution, and diversity of the bacterial communities in the rumen of cows fed different forages. FEMS Microbiol Ecol. 2010;74:61222.

67. Thomas F, Hehemann JH, Rebuffet E, Czjzek M, Michel G. Environmental and gut bacteroidetes: the food connection. Front Microbiol. 2011;2:93.

68. Turnbaugh PJ, Ley RE, Mahowald MA, Magrini V, Mardis ER, Gordon JI. An obesity-associated gut microbiome with increased capacity for energy harvest. Nature. 2006;444:1027-31.

69. Chen YB, Lan DL, Tang C, Yang XN, Li J. Effect of DNA extraction methods on the apparent structure of yak rumen microbial communities as revealed by $16 \mathrm{~S}$ rDNA sequencing. Pol J Microbiol. 2015;64:29-36.

70. Chevalier C, Stojanović O, Colin DJ, Suarez-Zamorano N, Tarallo V, Veyrat-Durebex C, et al. Gut microbiota orchestrates energy homeostasis during cold. Cell. 2015;163:1360-74.

71. Ley RE, Turnbaugh PJ, Klein S, Gordon JI. Microbial ecology: human gut microbes associated with obesity. Nature. 2006;444:1022-3.

72. Etxeberria U, Arias N, Boqué N, Macarulla MT, Portillo MP, Martínez JA, et al. Reshaping faecal gut microbiota composition by the intake of trans-resveratrol and quercetin in high-fat sucrose diet-fed rats.J Nutr Biochem. 2015;26:651-60.

73. Remely M, Tesar I, Hippe B, Gnauer S, Rust P, Haslberger AG. Gut microbiota composition correlates with changes in body fat content due to weight loss. Benefic Microbes. 2015;6:431-9.

74. Pedersen R, Andersen AD, Mølbak L, Stagsted J, Boye M. Changes in the gut microbiota of cloned and non-cloned control pigs during development of obesity: gut microbiota during development of obesity in cloned pigs. BMC Microbiol. 2013;13:30.

75. Atasoglu C, Newbold CJ, Wallace RJ. Incorporation of [15N] ammonia by the cellulolytic ruminal bacteria Fibrobacter succinogenes BL2, Ruminococcus albus SY3, and Ruminococcus flavefaciens 17. Appl Environ Microbiol. 2001;67:2819-22.

76. Popova M, Guyader J, Silberberg M, Seradj AR, Saro C, Bernard A, et al. Changes in the rumen microbiota of cows in response to dietary supplementation with nitrate, linseed, and saponin alone or in combination. Appl Environ Microbiol. 2019;85:e02657-18.

77. Kim H, Lee I, Kwon Y, Kim BC, Ha S, Lee JH, et al. Immobilization of glucose oxidase into polyaniline nanofiber matrix for biofuel cell applications. Biosens Bioelectron. 2011;26:390813.

78. Russell JB, Jeraci JL. Effect of carbon monoxide on fermentation of fiber, starch, and amino acids by mixed rumen microorganisms in vitro. Appl Environ Microbiol. 1984;48:211-7.

79. Russell JB, Martin SA. Effects of various methane inhibitors on the fermentation of amino acids by mixed rumen microorganisms in vitro. J Anim Sci. 1984;59:1329-38.

80. Kanegasaki S, Takahashi H. Function of growth factors for rumen microorganisms I. Nutritional characteristics of Selenomonas ruminantium.J Bacteriol. 1967;93:456-63.

81. Allison MJ. Biosynthesis of amino acids by ruminal microorganisms. J Anim Sci. 1969;29:797807.

82. Nolan JV. Nitrogen kinetics. In: Forbes JM, France J, editors. Quantitative aspects of ruminant digestion and metabolism. Wallingford: CAB International Press; 1993. p. 123-43. 